Review Paper:

\title{
Low Lumbar Fractures: Unique Biomechanics and Treatment Options
}

\author{
Kaveh Haddadi ${ }^{1}$ (D) Saeed Ehteshami ${ }^{1}$
}

1. Associate Professor of Neurosurgery, Spine Fellowship, Orthopedic Research Center, Mazandaran University Of Medical Sciences, Sari, Iran

$\begin{aligned} & \text { Use yur devic to scan } \\ & \text { and read the article online }\end{aligned}$
2020; 6(1):3-12. http://dx.doi.org/10.32598/irjns.6.1.2
doi: : http://dx.doi.org/10.32598/irjns.6.1.2

(c) (i) (9)

Article info:

Received: 10 Aug 2019

Accepted: 23 Nov 2019

Available Online: 01 Jan 2020

Keywords:

Lumbar region, Spinal

fractures, Treatment options

\section{ABSTRACT}

Background and Aim: Acute lower lumbar spinal fractures ( $L 4$ and $L 5$ ) can cause major neurologic damage and mechanical instability. The ultimate surgical method for the management of unstable lower lumbar spine fractures

Methods and Materials/Patients: Online search databases including Google scholar databases, PubMed and Ovid was performed using the keywords: Low lumbar, fractures, spine trauma, biomechanics, classification, anatomy, spinopelvic alignment, non-operative and surgical treatment options. Finally, about 47 related studies were identified and reviewed.

Results: The L4 and L5 vertebra and related discs contribute to $50 \%$ of the lordosis in the lumbar area. Fracture of the trapezoidal body of the fifth vertebra can considerably decrease this and change the L4-L5 and L5-S1 biomechanics. The lower lumbar spine, in contrast to the thoracolumbar junction, is secure by the pelvis and the robust musculature. There is great controversy about the treatment of lumbar burst fractures without neurologic deficit. The surgical indication and optimal procedure may be influenced by numerous aspects such as the severity of signs and symptoms, the amount of loss of vertebral body height and the involvement of the spinal canal, and finally, the stability of the posterior spinal components.

Conclusion: There is no consensus on what establishes the paramount treatment for low lumbar burst fractures. Conservative care has been related to acceptable outcomes for patients with a burst fracture which are neurologically intact. In more severe injuries, spinal decompression and stabilization via a posterior or anterior approach are based on the surgeon's preference. For lower lumbar burst fractures or fracture-dislocations of the lumbosacral junction with neurologic injury, posterior decompression and stabilization, and a period of rest and bracing for the preservation of lumbar lordosis are appropriate.

\section{* Corresponding Author:}

Saeed Ehteshami, MD.

Address: Orthopedic Research Center, Mazandaran University of Medical Sciences, Sari, Iran

Tel: +98 (11) 1133377169

E-mail:dr_saeed_ehteshami@yahoo.com 


\section{Highlights}

- Acute lower lumbar spinal fractures (L4 and L5) can cause major neurologic damages and mechanical instability.

- L4 and L5 fractures are different from the fractures in the thoracolumbar area. These differences include anatomy, biomechanics, classification, and treatment possibilities.

- The AO classification for thoracolumbar trauma is not useful for fractures of L4 and L5 vertebra.

- In more severe injuries, spinal decompression and stabilization via a posterior or anterior approach are the best decisions based on the surgeon's preference.

\section{Plain Language Summary}

Due to the growing prevalence of traumatic injuries, the incidence of spinal injuries has also remarkably increased. The classification, diagnosis, and treatment options of different types of spinal trauma and fractures are specified based on their different anatomic and biomechanical issues as well as their location in the spinal column among cervical to sacrum spine. This study presented the analysis of a thorough search on related studies and data on some unique spinal fractures occurring in lower spinal injury (fourth and fifth lumbar vertebra) and considered their special anatomy, biomechanics, classification, and treatment options.

\section{Introduction}

cute lower lumbar spinal fractures can cause major neurologic damage and mechanical instability. The ultimate surgical method for the management of unstable lower lumbar spine fractures remains questionable [1].

$\mathrm{L} 4$ and L5 fractures are different from those of the thoracolumbar area. These differences include anatomy, biomechanics, classification, and treatment possibilities. The infrequency of these damages is marked by their inadequate documents in the literature. Treatments need to be customized and the recommendations for thoracolumbar trauma management cannot essentially be shifted to low lumbar trauma [1, 2].

The ideal treatment of thoracolumbar and lumbar fractures has remained controversial. The exclusive features of the lower spine and insufficient literature on the fractures in this area are still a challenge for making helpful decisions [3].

Given the controversial available literature about the management of low lumbar fractures, this review aims at highlighting the various characteristics and treatment options of these unique spine fractures.

\section{Methods and Materials/Patients}

Online databases search including Google scholar databases, PubMed and Ovid were performed using the keywords: low lumbar, fractures, spine trauma, biomechanics, classification, anatomy, spinopelvic alignment, non-operative and surgical treatment options. Exclusion criteria were texts published in any language other than English. Significant training and publishing in this field are very limited, so we were obligated to use some existing old basic articles published before 2000 except for other new ones. Finally, about 47 related studies were identified and reviewed.

\subsection{Anatomy}

About half of the lumbar lordosis cases arise from complications in the L 4 and $L 5$ vertebrae and the related discs [4]. Fracture of the trapezoidal body of the fifth vertebra can considerably decrease this lordosis and change the L4-L5 and L5-S1 biomechanics [4-6]. A narrow spinal canal has a possibility for isolated nerve root injury in burst fractures or fracture-dislocation. The position of the lumbosacral junction inside the pelvic, the iliolumbar tendons, and the main muscle support sets need an extraordinary level of energy transmission to lead to major damages to the lower lumbar vertebrae $[5,6]$.

Usually, an approach to the lower lumbar spine via the anterior trajectory can be problematic because of the 
great vessels near the anterior vertebral structures. Although anterior entrance to the L4-L5 and L5-S1 disc is usually preferred, access to the vertebral body is more challenging $[6,7]$.

\section{Biomechanics}

Developing the 5-point criteria by White and Panjabi was a milestone for the description of stability and instability of thoracolumbar burst fractures, linking biomechanical, clinical, and anatomical viewpoints using the incapability to preserve fundamental integrity under physiological pressure to avoid the progression of neural discrepancy and pain $[7,8]$.

Burst fractures of the thoracolumbar spine characterize a range of spinal injuries that frequently arise due to axial loading and flexion compression damages of the spinal column. The mentioned fractures happen as a result of injury to at least the anterior and middle columns of the vertebral unit $[8,9]$. They often happen in the inferior thoracic and lumbar spine, probably owing to the great compression forces produced through the bulk of the inflexible thoracic ribs and the pelvic on the flexible middle area between them, which turns as the movable part of the spinal column. They are perceived universally in patients due to falling from height or high-speed road traffic accidents, or through rapid deceleration $[9,10]$.

There are distinctive anatomical features and particular biomechanics in the lower lumbar spine (L4-L5) which affect the reaction to trauma and can support diverse managements in this fracture [11].

Regular lordosis of the lower lumbar L4 spine permits the midpoint of gravity to drop posterior center of the body of L4 vertebra (Figure 1), causing fractures of lower lumbar less vulnerable to collapse or kyphosis which

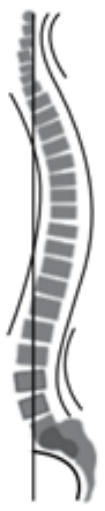

Figure 1. Center of gravity posterior to the body of L4 [3] is routine in the thoracolumbar junction $[3,12]$. Neurologic problems can be restricted via a wide neural canal, making the cauda equine less prone to damage, and increase the rate of recovery [13].

Lastly, the position of L5 on the edge of the upper part of the pelvic and ligaments between lumbar and sacroiliac regions makes a fixed situation for the uncommon lesions of this vertebra [3, 14, 15] (Figure 2). The practical importance of the flexibility of the lumbar spine leads us to control the degree of the fixation and stabilization of the moveable parts through the treatment [4, 15-17].

The lower lumbar spine, in contrast to the thoracolumbar junction, is protected by the pelvis and the strong musculature. Motor vehicle accidents, falling, or severe crush injuries occur in this area of the spine. Therefore, flexion-distraction injuries (Type B in AO spine injury classification system) are uncommon [4].

In these injuries, the anterior structures are commonly compromised. Type A fractures can cause variable amounts of vertebral body damage. Fracture-dislocation with displacement results in substantial lumbar disc disruption and a decrease of load-bearing capability. Defects of the anterior column make decision-making more challenging [18-20]. Anterior column insufficiency in the acute phase is associated with sagittal balance distortion. Deformity of the coronal plane will similarly cause an imbalanced load on the facet with probably faster degenerative alteration $[4,8,20]$.

Structurally, the surgeon must be conscious that distal sacral fixation points are instinctively fragile in contrast to pedicle insertion in the proximal lumbar spine [4, 15]. The distal fixation points could fail in aggregated anterior column discrepancy. Low lumbar fractures near the sacro-pelvic junction are difficult to brace. Biomechanical data have confirmed the increased shifted load over
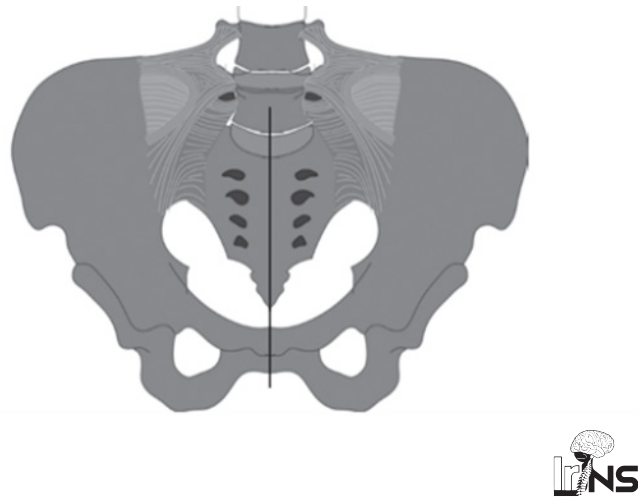

Figure 2. L4 and L5 stability by their lumbar ilio-sacral ligaments and their position under the upper part of the pelvis [3] 

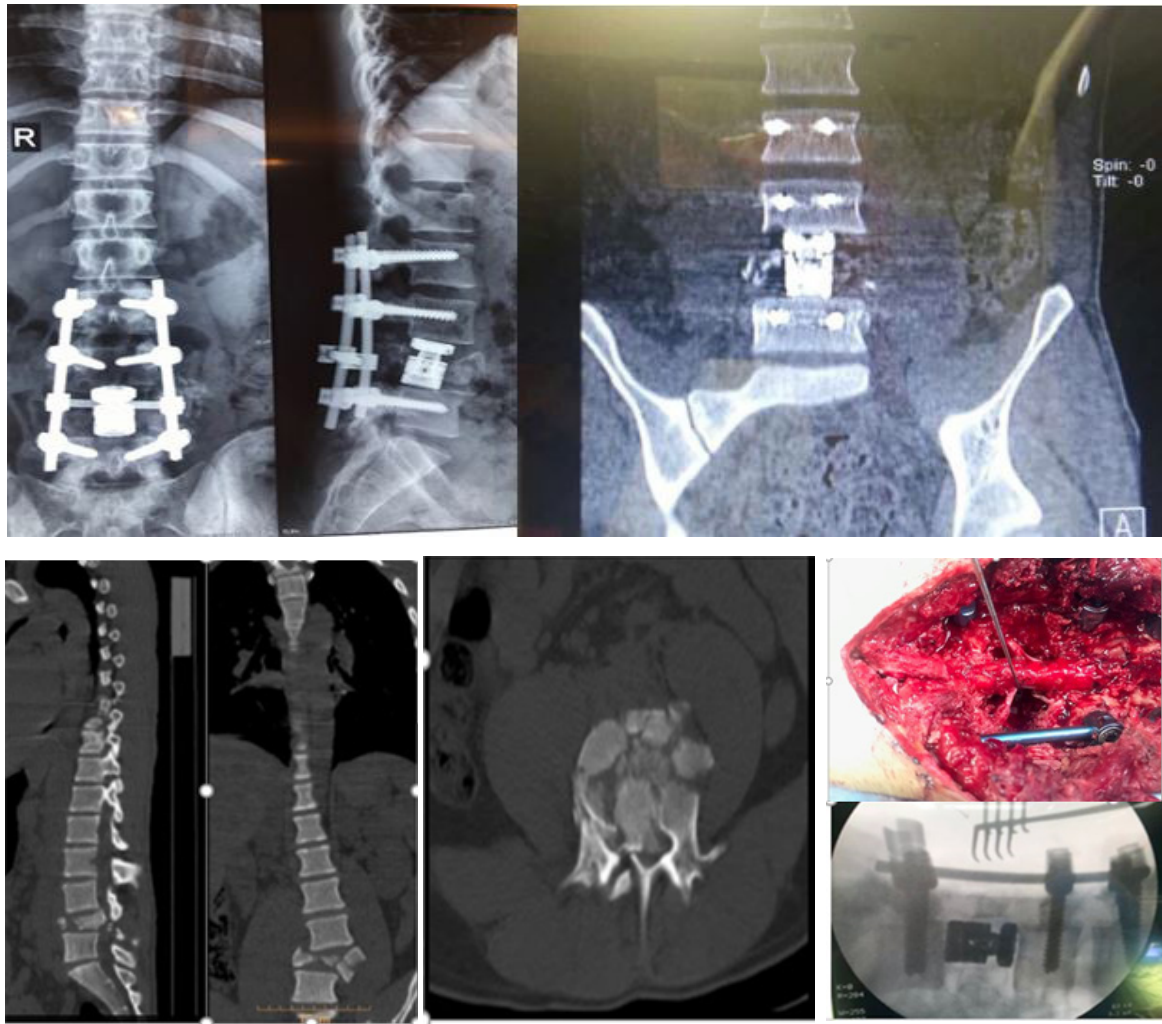

\section{NS}

Figure 3. Pre-operative and intra-operative and 2-year post-operation of a severe $L 4$ burst fracture with young patient without neurological deficits treated by 1-stage vertebrectomy, titanium mesh implantation, or tricortical graft and pedicle screw fixation.

Note, nerve hook retracts gently the L4 nerve root and prepares a space for cage insertion (Our practice in Spine Center of Mazandaran University of Medical Sciences, Iran).

the lumbosacral junction once TLSO braces are used. This bracing needs pelvic immobilization by the insertion of a distinct thigh in the brace or cast [16].

\subsection{Classification}

This arrangement system would eliminate some common fractures and contain infrequent sub-groups [18].
The compression and burst fracture, (Type A in AO spine injury classification system) happen in the lower lumbar spine. AO Type $B$ and $C$ fractures like the Chance fracture and fracture-dislocations are extremely rare and are different from the fractures seen at the thoracolumbar area and need a special classification system [18]. Such a classification system for low lumbar fracture must
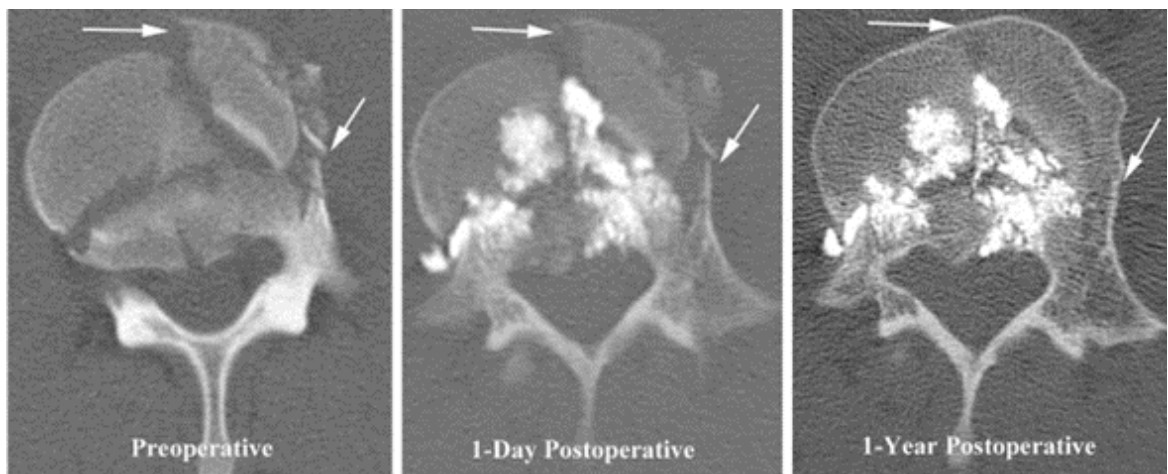

Figure 4. Pre-operative, just post-operative, and 1-year post-operative axial computed tomography imaging of lumbar L4 burst fracture with minimal loss of height and canal compromise, the axial images revealing bone growth at the fracture lines (arrows) [47]. 
include 1. Process fractures like transverse or spinous, 2. Fractures related to sacral and pelvic trauma and 3. Fracture-dislocations of L5 as traumatic spondylolisthesis $[19,20]$. The decision for diagnosis, spinal cord injury detection, classification, and treatment selection imaging like CT scan and MRI have important roles [21].

A valuable classification of lower lumbar fractures may contain:

1. Isolated process fractures such as transverse process or spinous fractures;

\section{Type $A$ as compression and burst fractures;}

3. Fracture-dislocations as traumatic spondylolisthesis [19];

4. Lumbosacral junction trauma linked by pelvic fractures [20];

\section{Mixed and miscellaneous injuries [4].}

\section{Incidence}

Lower lumbar injuries are relatively rare and these fractures contain $14 \%$ of all thoracolumbar injuries and are the consequence of high-impact trauma [2].

One multicenter study revealed $31 \mathrm{~L} 4$ and $\mathrm{L} 5$ burst fractures admitted from three spine departments over 16 years [16]. Some other small series frequently include a mixed population of patients and mixed treatment approaches amenable to change over time [22-26].

In a retrospective unique presentation in the Auckland region of New Zealand, over five years, the Trauma Unit of New Zealand reported an analysis of 7,041 admittances with a total of 824 spine injuries (351 cervical, 218 thoracic, 255 lumbar) [24]. Of the 255 lumbar spine injuries, only 63 involved the $L 4$ and $L 5$ vertebrae. The latter study comprised 37 process fractures principally transverse processes and of these patients, 21 cases were accompanied by major pelvic fractures. There were 14 compression type fractures, 6 burst type fractures, and 3 fracture-dislocations. One fracture of the pedicle was observed and in 2 cases, the fracture was unclassified. Noticeably, the incidence of $L 4$ and $L 5$ fracture leading to neurologic damage or major instability such as burst fractures or fracture-dislocations is small, signifying only $1.1 \%$ of spinal fractures in a report [27].

\section{Treatment Options}

There is a great controversy on the treatment of lumbar burst fractures without neurologic deficit [26, 27]. Surgical management classically includes 1 . A retroperitoneal corpectomy; 2. Posterior pedicle screw fixation ; or 3. A combination of them. The surgical indication and optimal procedure can be influenced by numerous factors such as the severity of signs and symptoms, the amount of vertebral body height loss and spinal canal involvement, and finally, the continuity of the posterior spinal components [27-29].

The management of burst fractures in acute spinal injuries denotes a complex decision procedure [30]. Some considerations should be evaluated to choose the best approach to continue. Posterior-only approaches are broadly applied, however, failure to retain the sagittal plane improvement has been detected [31]. Though, once the main aim is the decompression of the spinal cord and stabilization of the spine unit, the anterior approach would be the optimal method [32]. This approach delivers direct decompression of the neural elements, making proper anterior support and load sharing through the usage of a cage or graft [33]. Conversely, extreme blood loss, injury of the abdominal wall, damages to the diaphragm, and incisional problems are associated with the anterior method [34]. Newly, mini-open methods to the thoracolumbar spine have been revealed to be safe and effective in the management of numerous spinal disorders including vertebral fractures, with lowest blood loss, muscle injuries, and pain [33, 34].

The aims of thoracolumbar fracture treatment are returning spine stability and achieving spinal cord decompression to attain quick mobility in patients [35-40]. The organization of thoracolumbar burst fracture is varied, based on several mechanisms. Fracture neurological status, morphology, and the tendency of physicians all play a vital role in defining which approach among the anterior, posterior, or combined approaches are to be employed [40-42]. Burst fractures of the lower lumbar spine (L4-L5) have exclusive biomechanical and neurological characteristics similar to burst fractures in other areas of the spinal column $[40,41]$. Therefore, there has been great controversy concerning what establishes the paramount treatment for low lumbar burst fractures. Useful treatment includes quick and dynamic mobilization looks proper for stable compression fractures. It could similarly be applied to isolated process fractures without significant accompanying pelvic fractures $[35,36]$.

For burst type fractures without neurological deficit, several studies have recommended that conservative treatment was related to an acceptable outcome. Conventional care contains: 1 . Bed rest; 2 . Bracing of the low- 
er lumbar spine [35-38]. It looks very doubtful that bed rest or postural reduction leads to major vertebral height reconstruction or any improvement in lumbar lordosis after a burst trauma. Bracing must consist of a TLSO by a thigh extension. It is possible that initial mobilization in a brace may be related to more loss of anterior vertebral height and decreased lordosis. The short-term functional results for this method of treatment have been acceptable. Long-term complications include the likelihood of painful deterioration associated with disc and endplate damage and the progression of degeneration with a potential for developed spinal stenosis [36-39].

Sometimes in surgical approaches via posterior corridor wherever there are fractures with cauda equina injury; facetectomy, open reduction of fracture-dislocations, or canal decompression and impaction of retro-pulsed bony fragments away from compressed neural elements are obligated. Neurologic recovery after compressive damage to the cauda equina and nerve roots is reflected to be more satisfactory than proximal neurologic injury. Decompression is a proper therapeutic decision for those patients with major neurological deficits [35-40].

Posterior or posterolateral fusion without stabilization can immobilize the fractured bony fragments when the fusion mass is solid. It is possible that early mobilization, while the fusion mass is growing, would cause a progressive decrease in vertebral height and lumbar lordosis [4, 31-33].

Internal fixation with older instruments like 1 . Harrington rod systems 2 . Segmental sublaminar wire-rod systems are evidently linked with poorer outcomes. The Harrington system may flatten lumbar lordosis once used to treat a low lumbar breakage [4, 36, 37, 41]. This was related to the early progress of proximal junctional syndrome. Segmental fixation with sublaminar wiring typically needs further extension of the equipment, and finally are related to the early development of injuries in adjacent segments. These systems for stabilization of lower lumbar fractures are not currently commonplace in spine surgery [21, 39-42].

Posterior pedicle screw fixation instruments need 2-level stabilization for one-level burst injuries, but this short-level stabilization might be unacceptable for fracture-dislocations. Because of the propensity for burst vertebra to consolidate, with loss of anterior column height, strongly constrained rigid systems are mandatory. Choosing a pedicle screw system needs sufficient screw dimension, suitable rod size, and stiff rod connection to the screws to counter against bending moments
[41-43]. The patient's physiognomies to be measured including insufficient pedicle size and sacral anatomy to normally insertion screws, and also acceptable bone solidity. Surgical issues to be optimized consist of: 1 . Exact insertion with at least posterior cortical damage; 2. Eighty percent pedicle filling; 3 . Screw placement to the anterior cortex to maximize grip inside the vertebral body; 4 . Bi-cortical screw insertion at S1; and 5. A concern of both the S1 body and alar screws to increase sacral fixation. The surgery should take an operational position that enhances the lordosis above the instrumented segments. The patient is placed prone with the hips and completely extended knees [40-42].

Anterior column reconstruction is a challenging issue. The lack of acceptable anterior stabilizing instruments sometimes means that both anterior and posterior surgery would be essential. Because of the great vessel positions, the anterior approach is technically dependent [41-43].

In lower lumbar burst fractures with excessive vertebral compression and neurologic damage, standard alternatives are open posterior decompression and stabilization with a pedicle screw system. The additional care might include bed rest or bracing to permit fracture union and this can ultimately prevent implant failure $[3,44,45]$.

In circumstances of fracture-dislocation at the lumbosacral junction, the major translation will cause injury to the disc space. This traumatic instability of the lumbar disc is possibly dissimilar to disc height loss by degeneration process, and significantly involve the load-bearing ability of the intervertebral disc. If open reduction and stabilization via a posterior method are achieved, and disc height is preserved, the bending moments on the instruments could result in implant failure. In this condition, inter-body support would be a treatment choice. Decisions contain the consumption of a cage device or a measured bone graft via a posterior (PLIF) or anterior (ALIF) approach based on the surgeon's preference $[3,41,42]$.

A mini-open true lateral trans-psoas approach has described for lumbar corpectomy through percutaneous pedicle screw fixation in the management of an acute lumbar burst fracture [44].

Today, 1-stage partial or complete vertebrectomy, titanium mesh implantation, or tricortical graft and pedicle screw fixation in the treatment of some lumbar burst fractures through a posterior approach is a treatment option. This can be achieved using expandable cages only when it is used for the posterior approach. They obviate the need for an anterior approach to reconstruct the ver- 
tebral body. Meticulous care must be taken to reserve the spinal nerve roots $[45,46]$ (Figure 3 ).

In some selected chronic fractures, vertebroplasty intervention with close post-operative clinical monitoring has been described as a standalone treatment, and it offers the advantages of less operative morbidity and maintenance of lumbar mobility in selected patients [47] (Figure 4).

\section{Conclusion}

Low lumbar spine fractures are relatively rare and have different injury configurations, biomechanical and neurological landscapes compared with thoracolumbar fractures. Their management requires modification based on the pattern of trauma, neurologic injury, biomechanical insufficiencies, and the restrictions of surgical instruments and all available approaches. Thus, there has been great controversy concerning what establishes the paramount treatment for low lumbar burst fractures. Conservative care has been related to respectable outcomes for patients with a burst fracture without neurologic deficit. In more severe injuries, decisions contain spinal decompression and stabilization via a posterior or anterior approach based on the surgeon's preference. For lower lumbar burst fractures, or fracture-dislocations of the lumbosacral junction with neurologic injury, posterior decompression and stabilization, and a period of rest and bracing for re-establishing lumbar lordosis is appropriate.

\section{Ethical Considerations}

\section{Compliance with ethical guidelines}

As there is no animal or human research reported in this letter, there was no need for ethics board approval.

\section{Funding}

This research did not receive any specific grant from funding agencies in the public, commercial, or not-forprofit sectors.

\section{Conflict of interest}

The authors declared no conflict of interest.

Authors' contribution

Both authors contributed equally in writing this review.

\section{References}

[1] Magerl F, Aebi M, Gertzbein SD, Harms J, Nazarian S. A comprehensive classification of thoracic and lumbar injuries. European Spine Journal. 1994; 3(4):184-201. [DOI:10.1007/ BF02221591] [PMID]

[2] Sansur $\mathrm{CH}$, Shaffrey $\mathrm{Cl}$. Diagnosis and management of low lumbar burst fractures. Seminars in Spine Surgery. 2010 22(1):33-7 [DOI:10.1053/j.semss.2009.10.002]

[3] Daniel albert Oramírezislas, JOsémaría Jiménez Ávila. L4 fractures, biomechanics of cure foretold. Coluna/Columna. 2014 13(4):315-7. [DOI:10.1590/S1808-18512014130400475]

[4] An HS, Vaccaro A, Cotler JM, Lin S. Low lumbar burst fractures. Comparison among body cast, Harrington rod, Luque rod, and steffee plate. Spine. 1991; 16(8 Suppl):S440-4. [PMID]

[5] Varlotta GP, Lefkowitz TR, Schweitzer M, Errico TJ, Spivak J, Bendo JA, et al. The lumbar facet joint: A review of current knowledge: Part 1: Anatomy, biomechanics, and grading. Skeletal Radiology. 2011; 40:13-23. [DOI:10.1007/s00256-010-09834] [PMID]

[6] Su BW, Kim PD, Cha TD, Lee J, April EW, Weidenbaum M, et al. An anatomical study of the mid-lateral pars relative to the pedicle footprint in the lower lumbar spine. Spine. 2009; 34(13):1355-62. [DOI:10.1097/BRS.0b013e3181a4f3a9] [PMID]

[7] Vaccaro AR, Kepler CK, Rihn JA, Suzuki H, Ratliff JK, Harrop $\mathrm{JS}$, et al. Anatomical relationships of the anterior blood vessels to the lower lumbar intervertebral discs: analysis based on magnetic resonance imaging of patients in the prone position. Journal of Bone and Joint Surgery. 2012; 94(12):1088-94. [DOI:10.2106/JBJS.K.00671] [PMID]

[8] White AA, Panjabi MM. Clinical Biomechanics of the Spine. $2^{\text {nd }}$ Edition. Baltimore: Lippincott Williams \& Wilkins, 1990. https:// books.google.com/books?id=hDFsQgAACAAJ\&dq

[9] Denis $F$. The three column spine and its significance in the classification of acute thoracolumbar spinal injuries. Spine. 1983 8(8):817-31. [DOI:10.1097/00007632-198311000-00003] [PMID]

[10] Heary RF, Kumar S. Decision-making in burst fractures of the thoracolumbar and lumbar spine. Indian Journal of Orthopaedics. 2007; 41(4):268. [DOI:10.4103/0019-5413.36986] [PMID] [PMCID]

[11] Schouten R, Fisher CG. Fusion for Lower Lumbar (L3-L5) Fractures: Surgical Indications and Techniques. Semin Spine Surg. 2011; 23(4):249-56. [DOI:10.1053/j.semss.2011.05.006]

[12] Al-Khalifa FK, Adjei N, Yee AJ, Finkelstein JA. Patterns of collapse in thoracolumbar burst fractures. Journal of Spinal Disorders \& Techniques. 2005; 18(5):410-2. [DOI:10.1097/01. bsd.0000177957.11603.5c] [PMID]

[13] Kingwell SP, Noonan VK, Fisher CG, Graeb DA, Keynan O, Zhang $\mathrm{H}$, et al. Relationship of neural axis level of injury to motor recovery and health-related quality of life in patients with a thoracolumbar spinal injury. Journal of Bone and Joint Surgery. 2010; 92(7):1591-9. [DOI:10.2106/JBJS.I.00512] [PMID]

[14] Finn CA, Stauffer ES. Burst fracture of the fifth lumbar vertebra. Journal of Bone and Joint Surgery. 1992; 74(3):398-403. [DOI:10.2106/00004623-199274030-00011]

[15] Ghasemi A, Haddadi K, Khoshakhlagh M, Ganjeh HR. The relation between sacral angle and vertical angle of sacral curvature and lumbar disc degeneration: A case-control study. Medicine. 
2016; 95(6):e2746. [DOI:10.1097/MD.0000000000002746] [PMID] [PMCID]

[16] Wood K, Buttermann G, Mehbod A, Garvey T, Jhanjee R, Sechriest $V$. Operative compared with nonoperative treatment of a thoracolumbar burst fracture without neurological deficit: a prospective, randomized study. Journal of Bone and Joint Surgery. 2003; 85(5):773-81. [DOI:10.2106/00004623-20030500000001] [PMID]

[17] Seybold EA, Sweeney CA, Fredrickson BE, Warhold LG, Bernini PM. Functional outcome of low lumbar burst fractures. A multicenter review of operative and non-operative treatment of L3-L5. Spine. 1999; 24(20):2154-61. [DOI:10.1097/00007632199910150-00016] [PMID]

[18] Jacobus J. Kriek, ShunmugamGovender. AO-classification of thoracic and lumbar fractures-reproducibility utilizing radiographs and clinical information. European Spine Journal. 2006; 15(4):1239-46. [DOI:10.1007/s00586-005-0002-y] [PMID] [PMA CID]

[19] Leone A, Cerase A, Priolo F, Marano P. Lumbosacral junction injury associated with unstable pelvic fracture: Classification and diagnosis. Radiology. 1997; 205(1):253-9. [DOI:10.1148/ radiology.205.1.9314994] [PMID]

[20] Aihara T, Takahashi K, Yamagata M, Moriya H. Fracturedislocation of the fifth lumbar vertebra. A new classification. The Journal of Bone and Joint Surgery. 1998; 80(5):840-5. [DOI:10.1302/0301-620X.80B5.0800840]

[21] Ghasemi A, Haddadi K, Shad AA. Comparison of diagnostic accuracy of MRI with and without contrast in diagnosis of traumatic spinal cord injuries. Medicine. 2015; 94(43) [DOI:10.1097/MD.0000000000001942] [PMID] [PMCID]

[22] Van Savage JG, Dahners LE, Renner JB, Baker CC. Fracturedislocation of the lumbosacral spine: Case report and review of the literature. Journal of Trauma. 1992; 33(5):779-84. [DOI:10.1097/00005373-199211000-00033] [PMID]

[23] Mick CA, Carl A, Sachs B, Hresko MT, Pfeifer BA. Burst fractures of the fifth lumbar vertebra. Spine. 1993; 18(13):1878-84. [DOI:10.1097/00007632-199310000-00026] [PMID]

[24] Huang TJ, Chen JY, Hsu RW. Burst fracture of the fifth lumbar vertebra with unilateral facet dislocation: Case report. Journal of Trauma. 1994; 36(5):755-7. [DOI:10.1097/00005373199405000-00031] [PMID]

[25] Fredrickson BE, Yuan HA, Miller H. Burst fractures of the fifth lumbar vertebra. A report of four cases. Journal of Bone and Joint Surgery. 1982; 64(7):1088-94. [DOI:10.2106/00004623198264070-00022] [PMID]

[26] Haddadi K, Yosefzadeh F. Epidemiology of Traumatic Spinal Injury in north of Iran: A prospective Study. Iranian Journal of Neurosurgery. 2016; 1(4):11-4. [DOI:10.18869/acadpub.irf jns.1.4.11]

[27] Robertson PA, Fractures MD. Fractures of L4 and L5 (Low lumbar fractures) [Internet]. 2012 [Updated: 2012 Sep 18] Available from: https://www.spineuniverse.com/professional/ pathology/trauma/fractures-14-15-low-lumbar-fractures

[28] Öner FC, Wood KB, Smith JS, Shaffrey Cl. Therapeutic decision making in thoracolumbar spine trauma. Spine. 2010; 35(21S):S235-44. [DOI:10.1097/BRS.0b013e3181f32734] [PMID]

[29] Heary RF, Salas S, Bono CM, Kumar S. Complication avoidance: thoracolumbar and lumbar burst fractures. Neurosurgery Clinics. 2006; 17(3):377-88. [DOI:10.1016/j.nec.2006.04.012] [PMID]
[30] Smith WD, Dakwar E, Le TV, Christian G, Serrano S, Uribe JS. Minimally invasive surgery for traumatic spinal pathologies: A mini-open, lateral approach in the thoracic and lumbar spine. Spine. 2010; 35(26S):S338-46. [DOI:10.1097/ BRS.0b013e3182023113] [PMID]

[31] Sasso RC, Cotler HB. Posterior instrumentation and fusion for unstable fractures and fracture-dislocations of the thoracic and lumbar spine. A comparative study of three fixation devices in 70 patients. Spine. 1993; 18(4):450-60. [DOI:10.1097/00007632 199318040-00008] [PMID]

[32] Dai LY. Remodeling of the spinal canal after thoracolumbar burst fractures. Clinical Orthopaedics and Related Research ${ }^{\circledast}$ 2001; 382:119-23. [DOI:10.1097/00003086-200101000-00018] [PMID]

[33] Verlaan JJ, Diekerhof CH, Buskens E, Van der Tweel I, Verbout $A J$, Dhert WJ, et al. Surgical treatment of traumatic fractures of the thoracic and lumbar spine: A systematic review of the literature on techniques, complications, and outcome. Spine. 2004 29(7):803-14.[DOI:10.1097/01.BRS.0000116990.31984.A9] [PMID]

[34] Dimar JR, Fisher C, Vaccaro AR, Okonkwo DO, Dvorak M Fehlings $M$, et al. Predictors of complications after spinal stabilization of thoracolumbar spine injuries. Journal of Trauma and Acute Care Surgery. 2010; 69(6):1497-500. [DOI:10.1097/ TA.0b013e3181cc853b] [PMID]

[35] Payer M, Sottas C. Mini-open anterior approach for corpectomy in the thoracolumbar spine. Surgical Neurology. 2008, 69(1):25-31. [DOI:10.1016/j.surneu.2007.01.075] [PMID]

[36] Alvine GF, Swain JM, Asher MA, Burton DC. Treatment of thoracolumbar burst fractures with variable screw placement or Isola instrumentation and arthrodesis: case series and literature review. Journal of Spinal Disorders \& Techniques. 2004; 17:251 64. [DOI:10.1097/01.bsd.0000095827.98982.88] [PMID]

[37] Briem D, Lehmann W, Ruecker AH, Windolf J, Rueger JM, Linhart W. Factors influencing the quality of life after burst fractures of the thoracolumbar transition. Archives of Orthopaedic and Trauma Surgery. 2004; 124(7):461-8. [DOI:10.1007/s00402-0040710-5] [PMID]

[38] Dimar JR, Wilde PH, Glassman SD, Puno RM, Johnson JR. Thoracolumbar burst fractures treated with combined anterior and posterior surgery. American Journal of Orthopedics (Belle Mead, NJ). 1996; 25(2):159-65. [PMID]

[39] Leferink V, Zimmerman K, Veldhuis E, Ten Vergert E, Ten Duis $H$. Thoracolumbar spinal fractures: Radiological results of transpedicular fixation combined with transpedicular cancellous bone graft and posterior fusion in 183 patients. European Spine Journal. 2001;10(6):517-23. [DOI:10.1007/s005860100319] [PMID] [PMCID]

[40] Parker JW, Lane JR, Karaikovic EE, Gaines RW. Successful shortsegment instrumentation and fusion for thoracolumbar spine fractures: A consecutive 41/2-year series. Spine. 2000; 25(9):115770. [DOI:10.1097/00007632-200005010-00018] [PMID]

[41] Andreychik DA, Alander DH, Senica KM, Stauffer ES. Burst fractures of the second through fifth lumbar vertebrae. Clinical and radiographic results. Journal of Bone and Joint Surgery. 1996 78(8):1156-66. [DOI:10.2106/00004623-199608000-00005] [PMID]

[42] Kocis J, Wendsche P, Visna P. Complete burst fracture of the fifth lumbar vertebra treated by posterior surgery using ex pandable cage. Acta Neurochirurgica. 2008; 150(12):1301 [DOI:10.1007/s00701-008-0149-5] [PMID] 
[43] Kareem H, Raza MH, Kontojannis V, Nimer A, Tsang K. Case series of posterior instrumentation for repair of burst lumbar vertebral body fractures with entrapped neural elements. Journal of Spine Surgery. 2018; 4(2):374. [DOI:10.21037/jss.2018.06.03] [PMID] [PMCID]

[44] Amaral R, Marchi L, Oliveira L, Coutinho T, Pimenta L. Acute lumbar burst fracture treated by minimally invasive lateral corpectomy. Case Reports in Orthopedics. 2013; 2013:953897. [DOI:10.1155/2013/953897] [PMID] [PMCID]

[45] Liu Y, Li G, Dong T, Zhang Y, Li H. One-stage partial vertebrectomy, titanium mesh implantation and pedicle screw fixation in the treatment of thoracolumbar burst fractures through a posterior approach. Clinics. 2014; 69(12):804-8. [DOI:10.6061/clinn ics/2014(12)03]

[46] Padalkar P, Virani N, Kathare A. Posterior reconstruction of vertebral body using expandable cage for $\mathrm{L} 5$ burst fracture dislocation: case report. Journal of Orthopaedic Case Reports. 2014; 4(2):5-9. [DOI:10.13107/jocr.2250-0685.157] [PMID] [PMCID]

[47] Tender GC, Serban D. Traumatic spinal fracture treated by vertebroplasty: A case report. Journal of Medical Case Reports. 2012; 6(1):390. [DOI:10.1186/1752-1947-6-390] [PMID] [PMCID] 
This Page Intentionally Left Blank 